\title{
ANEURYSM OF AN ANOMALOUS RIGHT SUBCLAVIAN ARTERY BY
}

\author{
W. C. D. RICHARDS AND C. E. ELLIOTT \\ From the Radcliffe Infirmary, Oxford
}

An anomalous right subclavian artery arising from the left side of the aortic arch distal to the left subclavian artery was first described by Hunauld (1735). In most cases the artery passes behind the osophagus to reach the right side of the neck. The defect is usually attributed to a failure of development of the fourth right aortic arch, the caudal part of the right dorsal aorta persisting, sometimes with dilatation, to form the proximal part of the abnormal right subclavian artery. There are numerous accounts of this anomaly and they have been reviewed by Cairney (1925). Symptoms are unusual but in a small proportion of cases dysphagia is complained of. Bayford (1789) termed the difficulty in swallowing dysphagia lusoria.

\section{Case Report}

A lay brother in a religious order, aged 70 years, suddenly felt himself " choked by phlegm " and became so distressed that his friends thought he was about to die. When seen by his doctor shortly afterwards his general condition had improved but he was still breathing stertorously. A swelling of the neck, most marked above the right clavicle, was noted. On admission to hospital he was able to give the following story. For one year he had been short of breath when doing heavy work but had previously been in good health. Six weeks before he had noticed a painless swelling of the right side of his neck which had since been gradually increasing in size. He had experienced difficulty in swallowing, especially when eating solid foods, for about one month. During a recent cold he had noticed that " phlegm stuck in his throat."

On examination he was found to be a very fat man, breathing stertorously, but cheerful and not cyanosed. His neck was unusually thick and showed a diffuse doubtfully pulsatile swelling on both sides of the trachea. The posterior pharyngeal wall was firm and pushed forwards so that it almost touched the uvula. The temperature was $100^{\circ} \mathrm{F}$., respiratory rate 24 a minute, pulse rate 90 a minute. The pulse was regular in rhythm but was weak at the right wrist. The femoral pulses were present and equal. The blood pressure was $150 / 90 \mathrm{~mm}$. $\mathrm{Hg}$ in the right arm and $210 / 140 \mathrm{~mm} . \mathrm{Hg}$ in the left arm. The heart was enlarged and loud systolic and diastolic murmurs were heard over the præcordium, the diastolic murmur being best heard over the third left costal interspace near the sternum. Minimal crepitations were heard over both lung bases. The vocal cords moved normally.

Investigations included: $\mathrm{Hb}$. $15 \cdot 3 \mathrm{~g}$. per $100 \mathrm{ml}$; white blood cells 7900 per c.mm.; Wassermann reaction and Kahn negative. Electrocardiogram: ischæmic heart disease and sinus tachycardia. X-ray examination (Dr. F. Kemp): “ There is a large space-occupying lesion in the posterior mediastinum extending upwards into the neck anteriorly. The trachea is markedly displaced and narrowed." Barium swallow: "The œsophagus is displaced to the right with a deformity in the region of the aortic knuckle. The findings are compatible with a rupture of the aorta and extravasation of blood."

The diagnosis of a leaking aortic aneurysm was made. Treatment was essentially expectant in the hope that the aneurysm would seal. Penicillin to combat infection and sedatives to ensure rest were given. On the second day after admission a bluish discoloration of the chest due to subcutaneous extravasation of blood became visible, and this later spread downwards to the level of the nipples. His general condition improved slightly but on the fifth day after admission he suddenly became very dyspnœic and died a few hours later.

Necropsy. Externally, there was a diffuse swelling of both sides of the neck. The skin of the anterior surface of the chest showed bluish-yellow discoloration extending to the xiphisternum in the midline and to the level of the nipples elsewhere (Fig. 1).

The main finding on internal examination was an aneurysm of the first part of an aberrant right subclavian artery which had ruptured with resultant extravasation of blood into the tissues of the posterior 
mediastinum and neck. Three arteries arose from the arch of the aorta; in place of the innominate artery there was a common carotid trunk which divided almost at its origin to form the right and left common carotid arteries; to the left of this bicarotid trunk the left subclavian artery arose in the usual way; just

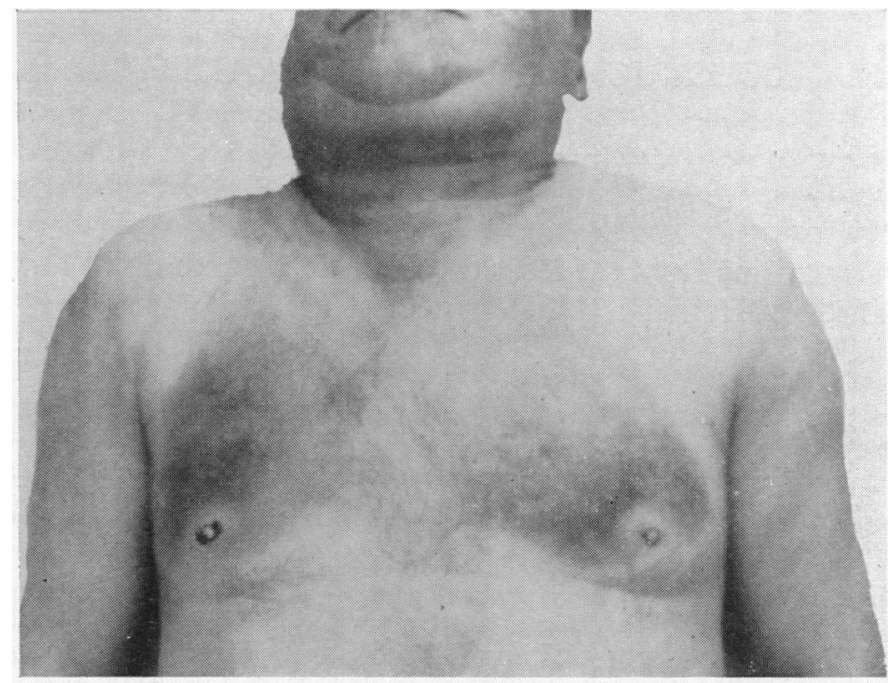

FIG. 1.-Extravasation of blood into the subcutaneous tissues of the chest. Swelling of the neck prominent on the right side.

distal to the left subclavian artery the anomalous right subclavian was given off from the posterior aspect of the aortic arch (Fig. 2). This artery passed laterally and upwards to the right behind the osophagus to gain its normal position in the root of the neck, and the right vertebral artery arose from it. At its origin the aberrant vessel was $3.5 \mathrm{~cm}$. in diameter and there was aneurysmal dilatation of its first $6 \mathrm{~cm}$., the maximum diameter being $4 \mathrm{~cm}$. The inner surface of the aneurysm showed gross atheroma with much adherent old and recent blood clot which almost occluded the lumen. In many places the aneurysm wall was extremely friable and on its superior surface there was an ill-defined rupture. A massive hæmatoma in the posterior mediastinum extended to the base of the skull and displaced the posterior pharyngeal wall forwards so that it was touching the base of the tongue. The œsophagus and the trachea were compressed and the œsophagus was displaced sharply to the right (Fig. 3). Extravasation of blood into the muscles, connective tissue, and subcutaneous tissues of the neck had occurred.

The aorta and the coronary, iliac, and femoral arteries all showed severe atheroma. There was left ventricular myocardial hypertrophy and fibrosis. The liver was enlarged. Other findings were pulmonary œdema, a Meckel's diverticulum, an umbilical hernia containing omentum, and a right hydrocele.

Microscopical examination of sections taken from the aneurysm wall confirmed its atheromatous nature. Near the site of the rupture there was much fibrinous thrombus on the thickened and ulcerated intima. The medial wall was necrotic or consisted of fibrous tissue and organizing blood clot in which a few isolated fragments of elastic tissue remained. The adjacent mediastinal tissues contained organizing blood clot.

\section{Comment}

Dysphagia was a symptom in the fatal cases of aberrant right subclavian artery described by Bayford (1789) and by Kellock and Batten (1895). Kirby (1818) described a case in which death was due to perforation of the abnormal artery by a bone which had been swallowed. Holzapfel (1899) considered that dysphagia lusoria was only to be expected when there was aneurysmal dilatation of the first part of the aberrant artery; Gross (1946), however, mentions that dysphagia in infants might be due to stretching of the artery to form a taut band across the esophagus, and that in later life arteriosclerotic changes might cause symptoms. In the case reported it is probable that the aneurysm had been present for some time. Dysphagia was complained of only when leakage of blood had produced a mediastinal hæmatoma. The collapse before admission was apparently the result of a rupture of the aneurysm which became partially sealed, only to break down again just before death. Even had the condition been correctly diagnosed during life it is 

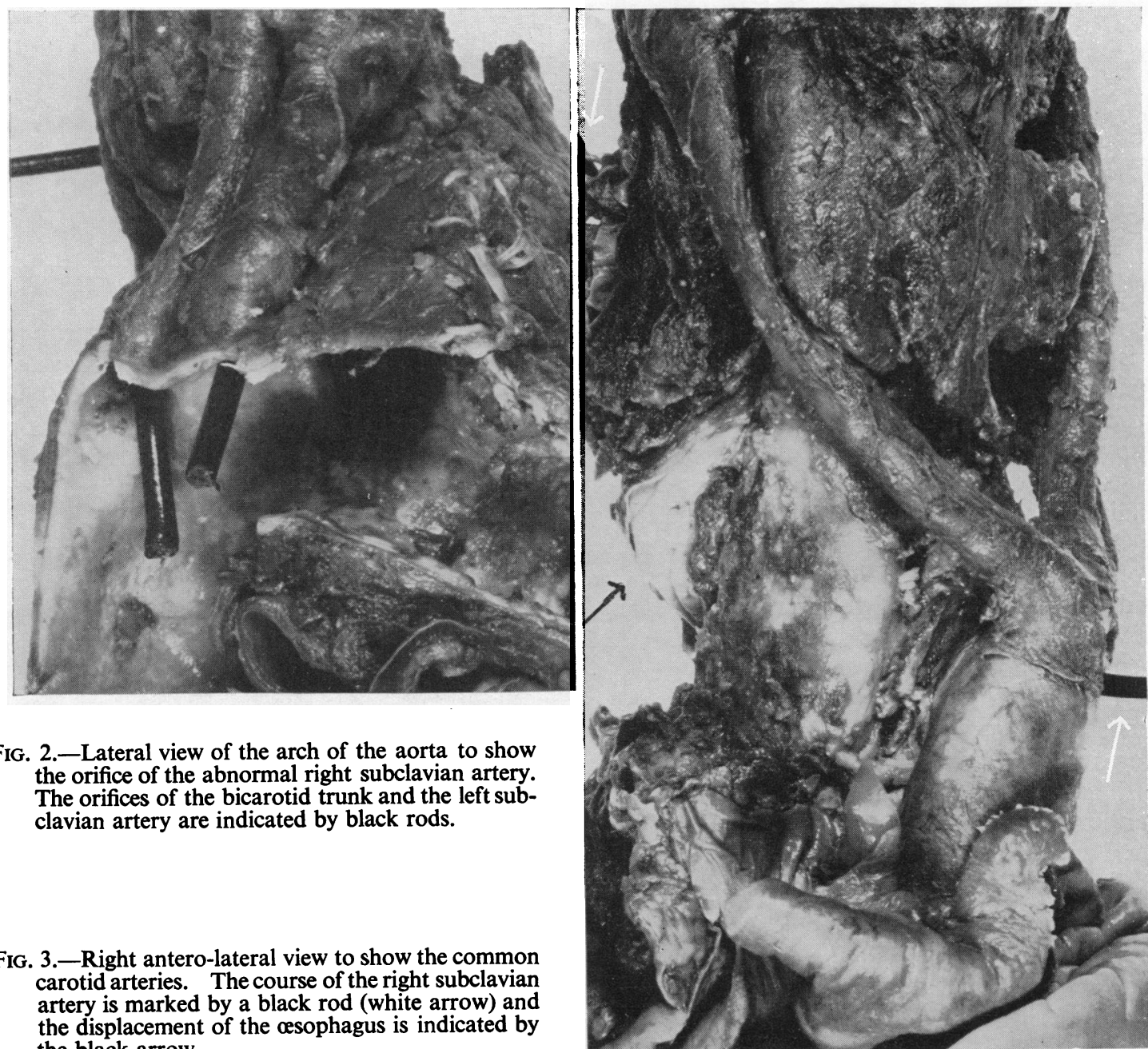

Fig. 2.-Lateral view of the arch of the aorta to show the orifice of the abnormal right subclavian artery. The orifices of the bicarotid trunk and the left subclavian artery are indicated by black rods.

FIG. 3.-Right antero-lateral view to show the common carotid arteries. The course of the right subclavian artery is marked by a black rod (white arrow) and the displacement of the osophagus is indicated by the black arrow.

unlikely that treatment would have been successful. An abnormal right subclavian artery should, however, be remembered as a rare cause of dysphagia, particularly as radiological diagnosis during life can be made and in children surgical treatment is possible (Gross, 1946; Gross and Neuhauser, 1951).

\section{Summary}

An unusual case in which rupture of an aneurysm of an anomalous right subclavian artery was associated with neck swelling, dysphagia lusoria, and subcutaneous extravasation of blood, is described.

We wish to thank Professor L. J. Witts and Dr. A. H. T. Robb-Smith for permission to publish this case, also Mr. M. Morris for the photographs.

Bayford, D. (1789). Mem. Med. Soc., Lond., 2, 271.

\section{References}

Cairney, J. (1925). J. Anat., Lond., 59, 265

Gross, R. E. (1946). Ann. Surg., 124, 532.

and Neuhauser, E. B. D. (1951). Paediatrics, 7, 69

Holzapfel, G. (1899). Anat. Hefte., 12, 369.

Hunauld, P. (1735). Histoire de l'Academie Royale, p. 20.

Kellock, T. H., and Batten, F. E. (1895). Lancet, 1, 1579.

Kirby, J. (1818). Dublin Hosp. Rep., 2, 224. 